Note: This is a pre-revision, pre-proofed version of a manuscript submitted to the journal Ecological Economics. The final version of the article has since been published, and it is that version of the article that should be used for reference, and for citation. That article is available at:

http://authors.elsevier.com/sd/article/S0921800913002140

The correct citation of the final version is:

West, J., Schandl, H., 2013. Material use and material efficiency in Latin America and the Caribbean. Ecological Economics 94, 19-27.

\title{
Material Use and Material Efficiency in Latin America and the Caribbean
}

James West ${ }^{\mathrm{a}}$ and Heinz Schandl ${ }^{\mathrm{a}, \mathrm{b}}$

${ }^{a}$ CSIRO Ecosystem Sciences, Social and Economic Sciences Program, Black

Mountain Laboratories, Clunies Ross St, Acton, 2601 ACT, Australia

${ }^{\mathrm{b}}$ ANU Crawford School for Economics and Government, Canberra, Australia

\begin{abstract}
Different world regions have followed very different trajectories for natural resources use over the recent decades. Latin America and the Caribbean have pursued a path to economic development based largely on exports of primary resources, notably of metals, energy and food. Adopting this path has characteristic environmental and social impacts. In this paper, we provide the first broad based estimate of material use and material efficiency for the region and 22 of its constituent countries, beginning in 1970 and extending to the onset of the global financial crisis in 2008. The results show a region with rapidly growing materials consumption and net exports of primary materials, which is simultaneously becoming less efficient at converting those resources into national income. Using an IPAT framework we found that population growth and rising per-capita incomes made broadly comparable contributions to growing material use, and that technological change as reflected in material intensity, did not moderate the growth dynamic. The trend of growing material intensity observed for the region as a whole also has occurred for many individual countries. This is in marked contrast to some other world regions, and is significant because it implies that many countries in Latin America and the Caribbean will confront even higher environmental pressures than expected as they expand their extractive industries to take advantage of new demand from other world regions, while simultaneously supplying the requirements for their own domestic industrial transformations and urbanization. The countries of the region will require welldesigned policies to mitigate the environmental and social impacts of its resource dependent development path, while maintaining future competitiveness.
\end{abstract}


Keywords: material use; material efficiency; material flow accounting; Latin America and the Caribbean; sustainable resource management policies

\section{Introduction}

The intent of this study is to provide new insights into material use and material efficiency patterns for Latin America and the Caribbean, and the drivers behind the observed patterns. To this end we constructed a new material flows data set which covers 22 countries within the region, for the period 1970 to 2008, using a standardized methodology based on that defined in (Eurostat 2011). This considerably extends the number of countries and the length of time series for which such standardized data is now available, and is important in facilitating more direct comparison with other national, regional, and global studies, such as (Gierlinger and Krausmann 2012, Krausmann et al. 2009, Krausmann, Gingrich and NourbakhchSabet 2011, Schandl and West 2010). Previous studies for Latin America have tended to provided much narrower coverage, either concentrating on individual countries e.g. Chile (Giljum 2004), Colombia (Perez Rincon 2006, Vallejo, Pérez Rincón and Martinez-Alier 2011), Ecuador (Vallejo 2010), and Mexico (Gonzalez-Martinez and Schandl 2008), or have provided comparative analysis for small groups of countries e.g. 5 countries (Russi et al. 2008).

We also develop an account of the degree to which this world region's sociometabolic profile is shaped by development abroad, highlighting how much of Latin America's economic development has been oriented towards increasing exports of primary resources. This is significant in that previous studies have linked such primary export driven patterns of development to economic structures with characteristic patterns of underdevelopment and inequality (Bunker 1984a, Giljum and Eisenmenger 2004).

From the turn of the millennium the global economy entered a period characterized by rising and more volatile prices for natural resources - fossil fuels, metals, food and water - driven by the dynamic growth of large developing economies, especially China (UNEP 2011). In such a rapidly changing context, governments increasingly require information systems that provide insight into the trends of natural resources production and use, to complement the set of economic indicators traditionally used for policy formation and planning. There is a need to broaden the compass employed in decision making (Bartelmus 2003). Two main systems have been employed to organize such information, the System of Economic and Environmental Accounts (SEEA) of the United Nations (Bartelmus 2007) and the material flows accounting (MFA) approach promoted by the Organization of Economic Cooperation and Development (Haberl et al. 2004). The latter approach is relevant to this study.

Material flow accounting has been used to assemble information on the material requirements of national economies since the 1990s, largely implementing a basic program set out in the late 1960s by Robert Ayres and Allen Kneese (FischerKowalski 1998). This accounting approach provides a knowledge base essential to quantifying the relative resource efficiencies and socio-metabolic performance of different national economies. More recently, the science and policy community has reached broad agreement on the methodologies to be employed in MFA (Fischer- 
Kowalski et al. 2011), and produced studies on global material use (Behrens et al. 2007, Krausmann et al. 2009, Schandl and Eisenmenger 2006), and for a number of world regions e.g. Europe (Weisz et al. 2006) and Asia and the Pacific(Schandl and West 2010) . ${ }^{1}$

\section{Methods and data sources}

The methods used to create the material flow account for Latin America and the Caribbean were largely the same as those used previously to assemble a similar database for the Asia Pacific region, as described in Schandl and West (2010). We provide here a summary and references to base data sources, along with detail on any significant departures from, or refinements of, the earlier methods. An expanded description is attached in Appendix A. Virtually all processing and transformation of data from the initial base data sets was carried out using the open source, freely available $\mathrm{R}$ language platform. Well accepted and publically accessible international data sources were used for base data, to the extent possible, however it was not feasible to avoid using some data sets which require subscription fees.

In compiling the data we adhered to the methodological guidelines set out in (Eurostat 2011) as closely as practicable. One significant variation is that the highest level four category breakdown of material flows used here is into biomass, fossil energy carriers, metal ores and industrial minerals, and construction minerals, whereas under (Eurostat 2011) the industrial minerals and construction minerals are combined under non-metallic minerals, and remain somewhat entangled even at the next level of disaggregation.

\subsection{Biomass}

Biomass flows were calculated independently for four sub-categories: primary crops, crop residues, grazed biomass, and wood.

Base data for the DE of primary crops is from (FAO 2011c), while data on exports and imports used to calculated domestic material consumption (DMC) was sourced from (FAO 2011d).

To calculate crop residues, harvest factors and recovery rates for specific crops and sub-regions within the Asia Pacific region were sourced from Haberl et al. (2007) and applied to the FAO crop production figures for each country.

To calculate grazed biomass, any energy "feed gap" between the energy embodied in animal products produced, and the animal specific energy available from feeds recorded in (FAO 2011a), was assumed to be made up, by ruminants, by intake of grazed biomass. The animal product, animal specific feed energies, and pasture energy factors were all sourced from (Wirsenius 2000). In addition to updated data sources, improvements over procedure used in (Schandl and West 2010) included

\footnotetext{
${ }^{1}$ There is a rich literature on material flow accounting at the national level mostly accessible in the Journal of Industrial Ecology and the Journal of Ecological Economics.
} 
adjusting animal products production to account for the trade in live animals recorded in (FAO 2011d), and inclusion of fish in feed inputs.

For wood, DE tonnages were calculated by applying factors supplied in (Eurostat 2011 ), to the appropriate volumes of all round woods extracted and reported in (FAO 2011b). There is an intentional mismatch between the scope of products included in calculating DE tonnages, and that used for traded tonnages. This is to better capture some major flows of near primary materials (Appendix A). All wood trade data was sourced from (FAO 2011b).

\subsection{Metal ores and industrial minerals}

The key base data sources used for DE for both sub-categories (metal ores, industrial minerals) were the same, and used in the same order of preference. Data from (Matos 2009) was used where available, and where not available (UN Statistics Division 2011b) used. Data for latter years not covered by (Matos 2009), for some of the most volumetrically important minerals, was sourced from individual commodity spreadsheets at (USGS 2011), in preference to using (UN Statistics Division 2011b) data. These sources typically stated production in terms of contained metals or compounds, so to convert this to tonnages of ore, grade factors have been applied. These grade factors used were largely derived from published and unpublished work by Gavin Mudd, notably (Mudd 2007b, Mudd 2007a), and as such reflect Australian averages. One important exception here was the grade applied to copper, which had an estimate of world average grades over time available from (Gerst 2008). Detail on how the disparate reporting bases used in the base data were treated, and on how coproduction and by-production were dealt with, are contained in Appendix A.

The base trade data required to calculate DMC from DE was sourced from (UN Statistics Division 2011a).

\subsection{Construction Minerals}

DE of construction minerals has been calculated by applying a time varying factor to DMC of cement. This approach is used in preference to compiling totals from the production statistics on individual construction minerals, due to the generally poor state of such statistics, and the relative reliability of statistics on cement. Statistics on cement production were sourced from (Matos 2009, USGS 2011), and cement trade from (UN Statistics Division 2011a). The time varying factors applied to calculate DE were the same as used in (Schandl and West 2010)., and were originally derived from (Krausmann et al. 2009).

\subsection{Fossil energy carriers}

The base data for all three subcategories here (coal, petroleum, natural gas) was sourced from (IEA 2011b, IEA 2011c). Only minor and straightforward transformations on this base data were required, e.g. applying a conversion factor to natural gas, given in energy terms in the original, to convert it to tonnes. 
As for wood and metal and industrial ores, the scope of products included differed for $\mathrm{DE}$ and net trade calculations.

\subsection{Materials efficiency measures}

The main indicator of materials efficiency used was material intensity (MI), and was derived from the total of the DMC calculated for each of the four major materials categories, divided by GDP. The GDP measure used was exchange rate based constant year 2000 \$US, sourced from (World Bank 2011).

\section{Results and Discussion}

\subsection{Trends in material use in Latin America and the Caribbean placed in a global context}

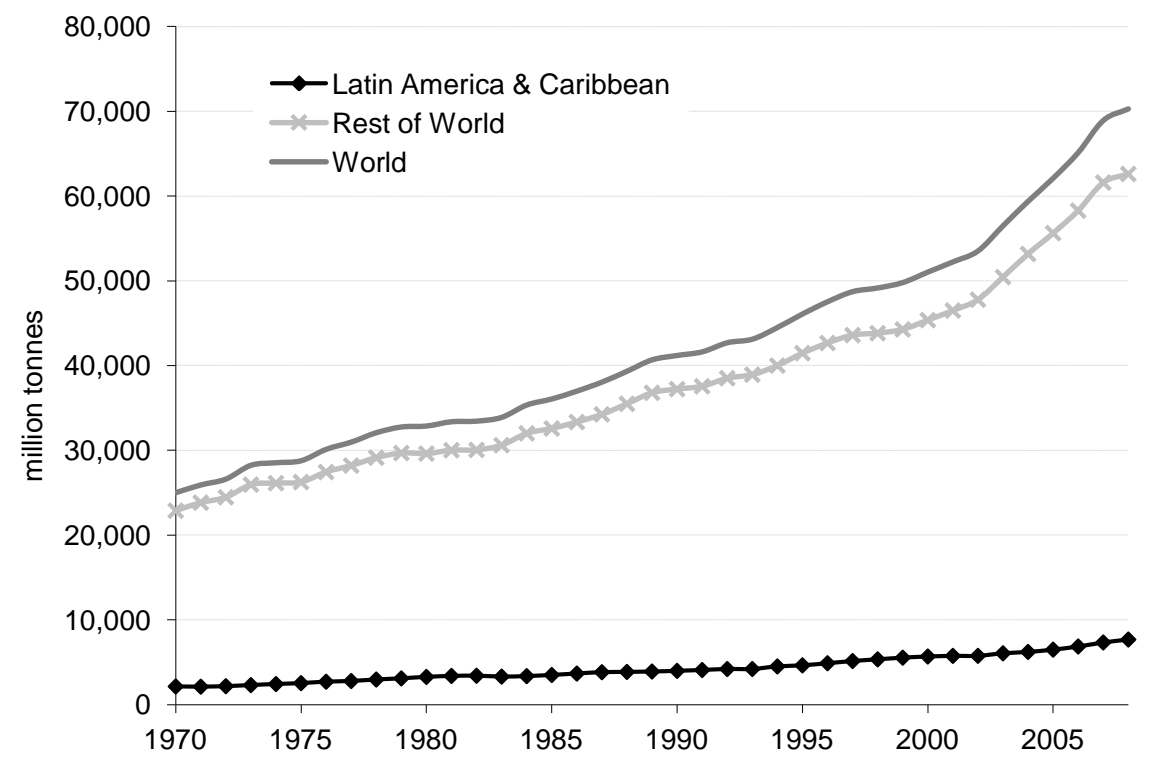

Figure 1 Domestic Material consumption (DMC) for Latin America and the Caribbean, Rest of the World, and World, for 1970 to 2008

Figure 1 shows that total domestic material consumption - of biomass, fossil fuels, metal ores and industrial and construction minerals combined - in Latin America and the Caribbean grew quite strongly when averaged over the period studied, from 2.1 billion tonnes in 1970 to 7.7 billion tones by 2008, a compounding growth rate of .3 .4 $\%$ p.a. Despite this growth, the region's share of global materials use is still relatively small, constituting only $11 \%$ of the global total in 2008 , up from $8.5 \%$ in 1970 . The region's DMC profile has, however, been strongly impacted by the global context. This is reflected in the rapid increase in material use since 2002, when growth accelerated to $4.9 \%$ p.a. compounding, compared to the $3.1 \%$ rate which 
characterized the period 1970 to 2002 . This acceleration was driven in large part by the rapid growth in demand for raw materials from Asia and the Pacific, particularly from China. Growth in global demand for primary materials since the mid 1980s has been dominated by the rapid industrialization and urbanization taking place in Asia (Schandl and West 2010, UNEP 2011), however the material demands of China's socio-metabolic transition since the new millennium transcends anything seen previously, due to the sheer size of the population involved. Where individual countries in Latin America and the Caribbean have been in a position to supply to this demand they have done so, leaving clearly visible imprints on material use patterns for the region as a whole.

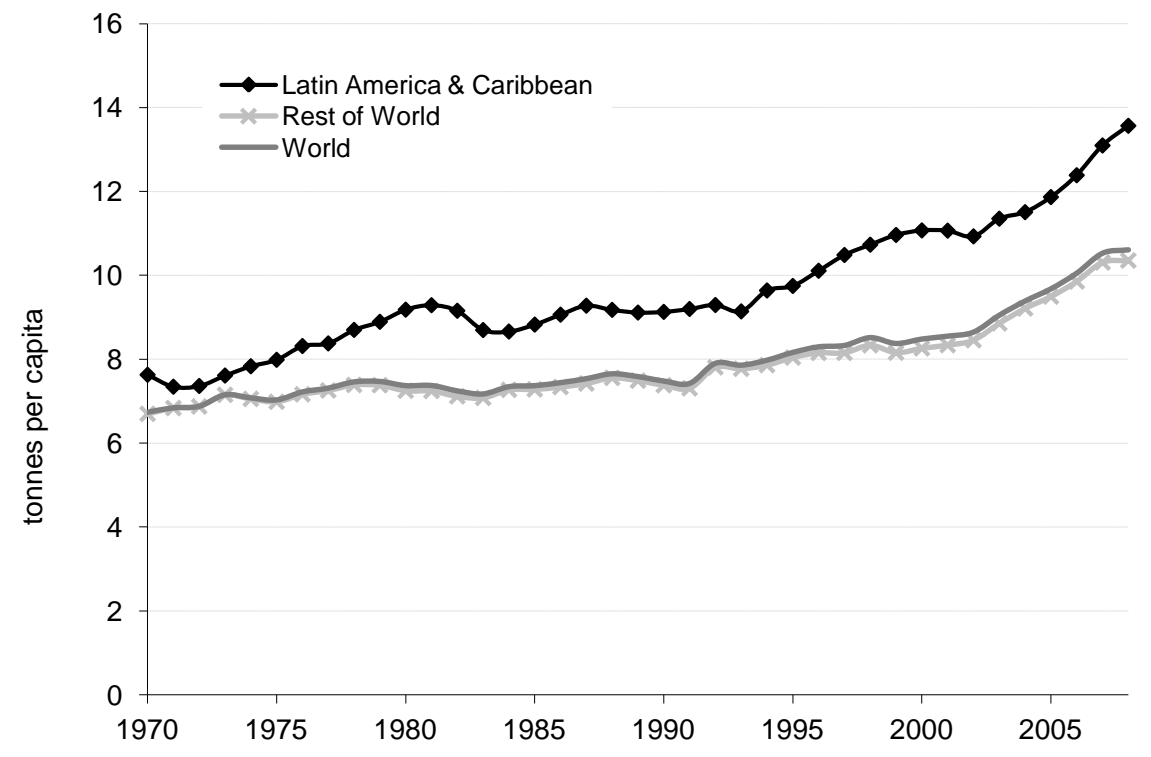

Figure 2 Domestic Material Consumption (DMC) per capita for Latin America and the Caribbean, Rest of the World, and World, for the years 1970 to 2008.

Figure 2 shows domestic material consumption on a per-capita basis, and reveals different phases in material use. Latin America and the Caribbean's per capita level of DMC began the period at 7.6 tonnes per capita, some $13 \%$ higher than the global average, and by 2008 was 13.6 tonnes per capita nearly, $30 \%$ higher than the corresponding global average. A period of strong DMC per capita growth in the 1970s was interrupted around 1981, reflecting a sovereign debt crisis in the region. The Latin American debt crises initiated a period of stagnation of material use until the early 1990s, when growth in DMC per capita re-emerged, and at a rate considerably faster than growth for the world as a whole. The new growth regime of the 1990s was related to new policies opening Latin American economies to international markets and competition, encouraging significant inflows of foreign investment focused on the mining, agricultural and forestry sectors. This increased the dependence of many countries in the region on exports of primary resources. It is noteworthy that this period of growth in DMC per capita took place despite it being a period of very low real prices for commodities, with 1992 to 2001 prices $37 \%$ below their average for the 1970s (Bértola and Ocampo 2012). Per-capita material use 
entered an even stronger growth phase from 2002, reflecting a resurgence of growth in DMC at the global level, and coinciding with a boom in commodity prices. Growth continued strongly through to at least 2008 and the onset of the Global Financial Crisis. The fact that growth in DMC per capita only moderated slightly in the region in 2008, rather than halting as seen at the global level, was mirrored by continued strong growth in DMC in the Asia-Pacific region (Schandl and West 2010), and highlights the degree to which Latin America's material flows are now influenced by demand from this region.

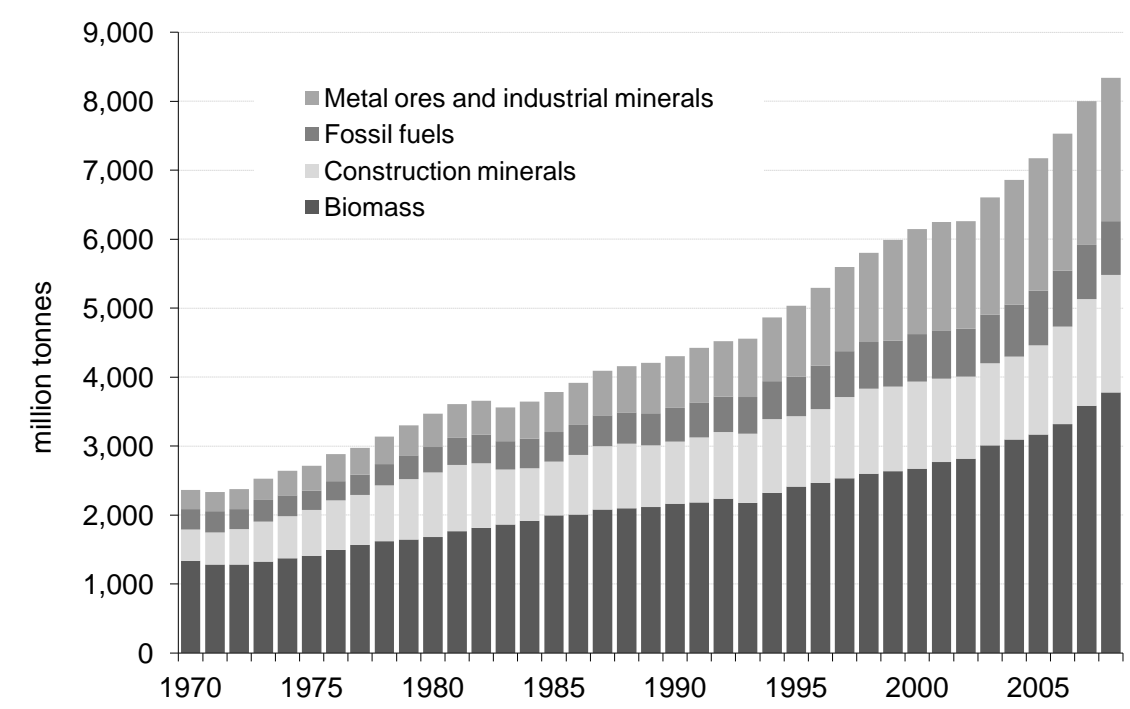

Figure 3 Domestic Extraction (DE) of materials in Latin America and the Caribbean, by major category of material, for 1970 to 2008 .

Figure 3 shows domestic material extraction in Latin America and the Caribbean for the four major constituent categories. While the total of all categories grew almost fourfold over the study period, the relative growth of individual categories has varied widely. In line with expectations for the socio-metabolic transition, which occurs as nations industrialize (Krausmann et al. 2008), the share of minerals has increased from $45 \%$ of the total to $55 \%$, while that of biomass has decreased accordingly. This decline in the share of biomass is nowhere near as dramatic as seen in some other regions, notably the Asia-Pacific (Schandl and West 2010), and this can be attributed to the extremely strong growth in total DE of biomass, which grew by $2.8 \%$ compounding over the full study period, with a marked acceleration from 2002. The increase in extraction of metal ores and industrial minerals has been particularly strong, growing at a compounding $5.5 \%$ p.a. over the study period, increasing its share of total DMC from $12 \%$ to $25 \%$. Fossil fuels, in contrast, have displayed the slowest growth of all categories, at $2.5 \%$ p.a. Not only has the share of fossil fuels declined markedly, from $13 \%$ in 1970 to $9 \%$ in 2008 , but total tonnages actually began to decline from 2006, unique among all material categories. Construction minerals grew at around $3.5 \%$ p.a., roughly equal to the overall growth rate in total $\mathrm{DE}(3.4 \%)$, reflecting its critical role in underpinning the ongoing process of urbanization and the expansion of associated infrastructure. 
Figure 4 demonstrates that the region was a net exporter of all four major materials categories for the entire study period, and so would appear to have a very high degree of resource security at the regional level. Figure 4 also highlights the degree to which Latin America and the Caribbean increased its role as a net exporter of primary materials from the early 1980s. A major driver of this was economic restructuring which followed the debt crisis, where development models based on state-led industrialization, often oriented towards import substitution of manufactures, were increasingly discarded and replaced with primary export oriented policies, aimed at generating the trade surpluses required to repay debt. There was a steep reduction in manufacturing's share of the economy during the early part of this phase (Bértola and Ocampo 2012). The regions physical trade balance increased from around 240 million tonnes in net exports in 1981 to peak at just below 700 million tonnes in 2005, a compounding growth rate of $4.6 \%$ for over that period. The decline in total net exports since 2005 can mainly be attributed to the rapid decline in exports of fossil fuels from 2005, which by 2008 were down to the lowest levels since 1996.

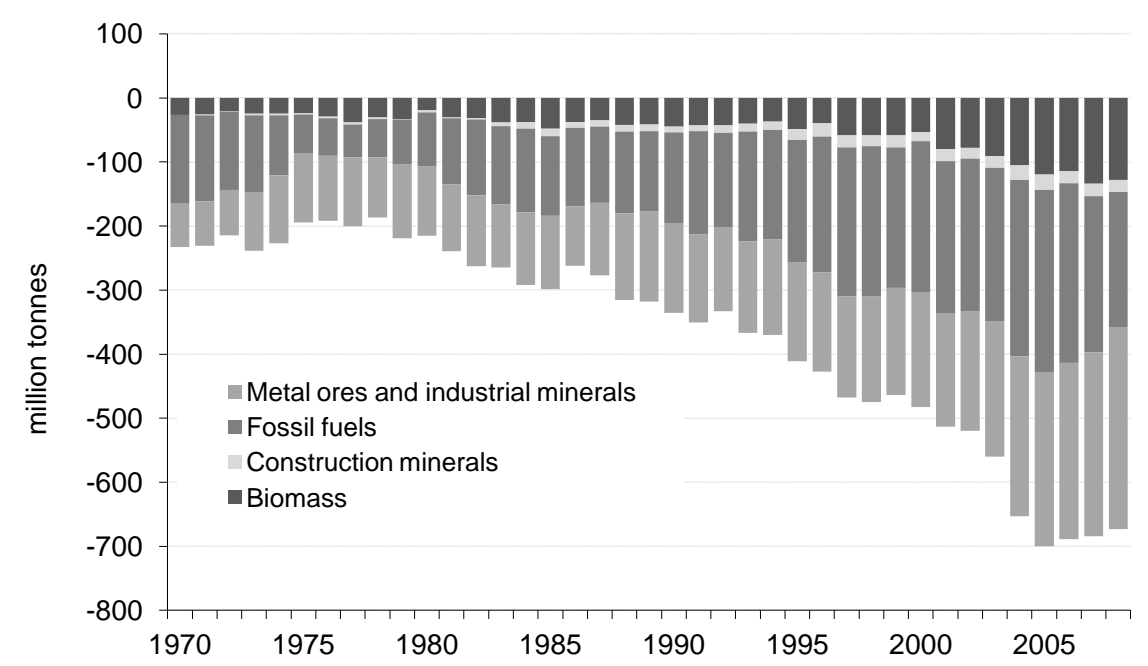

Figure 4 Physical Trade Balance (PTB) for Latin America and the Caribbean, by major category of material, for 1970 to 2008.

It is noteworthy that the decline in exports of fossil fuels predates the decline in DE of fossil fuels by a year, and also came at a time of rapidly increasing petroleum prices. Taken together, this suggests that relatively inelastic domestic demand has combined with domestic production constraints to rapidly decrease the regions "cushion" of surplus capacity in fossil fuels, at a time where such surplus capacity is more valuable than ever. The speed with which this decline took place will have major implications for the region's energy security in the near term, if the trend continues. Exports in the other materials categories since 2005 have either remained relatively stable, or continued to grow, with exports of metal ores and industrial minerals maintaining a growth rate of over $5 \%$ p.a. 


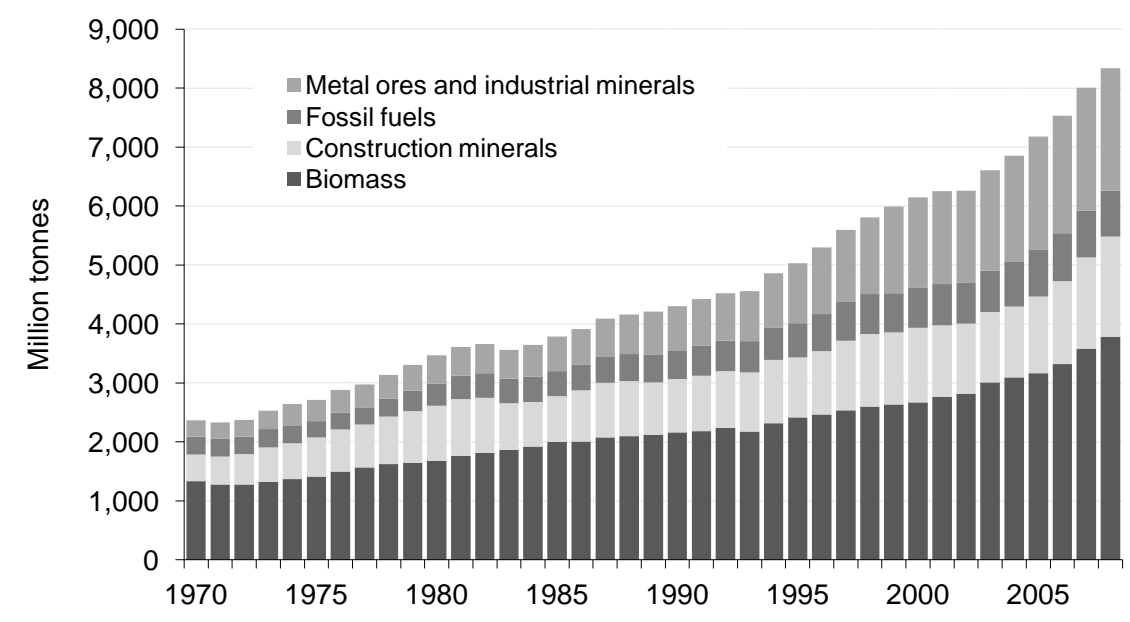

Figure 5. Domestic Material Consumption (DMC) in Latin America and the Caribbean, by major category of material, for 1970 to 2008 .

From figure 5 it is clear that domestic material consumption (DMC) is close to DE, a result of PTB typically being less than $10 \%$ of DE in volumetric terms. While this may reasonably reflect where the consumption of the substance or service of value embodied in the raw material occurs for construction materials and of fossil fuels, it will do a less satisfactory job of allocation for biomass, and will not attribute consumption of metal ores and industrial minerals at all well. This is due to the widely differing degrees to which different primary materials are concentrated before they are internationally traded. Most construction minerals do not undergo a high degree of concentration prior to being traded e.g. cement embodies much of the mass of the original rock mined, gravel and sand almost all of it. Similarly coal and products fractionated from petroleum do not lose much mass to discarded waste products between their extracted form, and the form in which they are traded internationally. Biomass does undergo significant concentration, especially when it is traded as animal products, which are mostly not counted as primary biomass, while the degree to which non-ferrous metals are concentrated between the ore as mined and the commodity internationally traded is often orders of magnitude This factor should be kept in mind when assessing the relative resource intensities of different economies (Schandl and West 2012).

\subsection{Material use trends in selected economies}

A subset of four countries from the region was selected for closer study, to explore some major differences in materials use patterns developing within the region. The initial screening for focus countries involved simply finding the 10 largest economies in GDP terms, as these countries are likely to have the most significant impacts both the regionally and globally. From this group of 10, Brazil was selected mainly due to the highly unusual pattern it exhibited with regard to the share of biomass in its materials consumption, although the fact that it is the region's largest economy by a large margin was also a consideration. Chile was selected because it had by far the largest DMC per capita, had experienced rapid affluence increases to a relatively high 
level, and because it had an extremely high metal ores and industrial minerals signature, far beyond that seen in developed or developing countries, in both share and absolute terms. Peru was selected as a poorer country which appeared to be at a much earlier stage of the type of minerals dominated development path followed much earlier by Chile. Colombia was selected due to it demonstrating relatively consistent improvements in materials efficiency over the long term, in marked contrast to the region as a whole, and nearly all of its constituent nations individually.

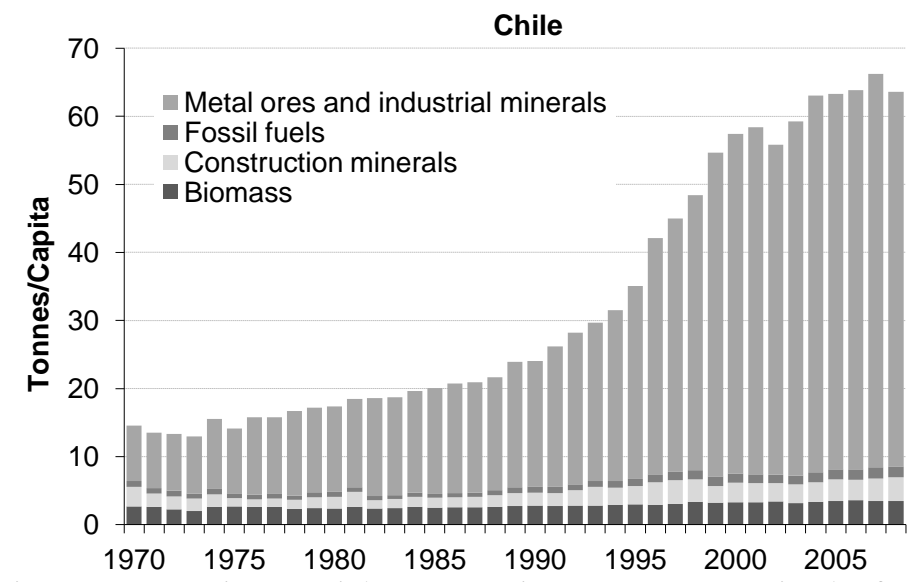

Figure 6 Domestic Material Consumption (DMC) per capita, by four major materials categories, for Chile

Chile's trajectory of DMC over time, shown in Figure 6, marks it as an extreme example of a economy which has pursued a development model based largely on extraction of natural resources for export. Chile's DMC stood at over 60 tonnes per capita from 2004 on, of which $87 \%$ is metal ores and industrial minerals. The corresponding share in 1970 was already 56\%, reflecting Chile's long held role as the world's single largest source of copper. This massive preponderance of metal ores and industrial minerals in Chile's DMC account highlights the effect that the concentration of mineral commodities prior to trade can have on national MFA balance sheets (Schandl and West 2012). Chile only "consumed" most of these metal ore in the sense that it converted the ore into highly concentrated forms, the vast majority of which were then exported to be converted into products which were actually used elsewhere, e.g. as copper wiring and pipes in Northeast Asia, while Chile retained the (worthless) bulk of the original ore in the form of mine tailings. The extremely high DMC per capita level by world standards is thus not reflected in proportionally high levels of material wealth and household consumption. Chile's DMC in the other three categories in 2008, while small in share terms, was above Latin American averages for construction minerals and fossil fuels (117\% and 158\% of the average respectively), but considerably below average for biomass (63\%). 


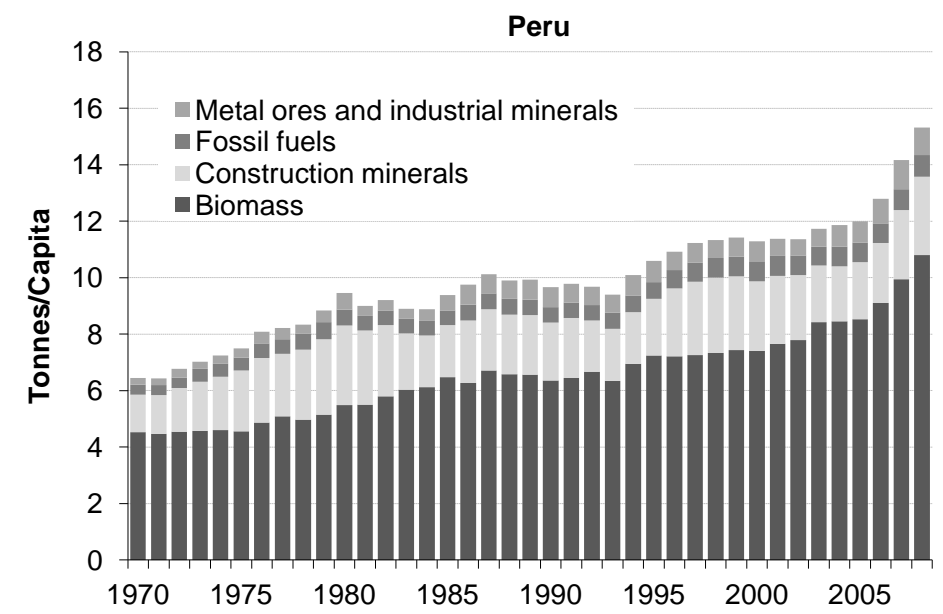

Figure 7 Domestic Materials Consumption (DMC) per capita, by four major materials categories, for Peru

Peru's DMC trajectory (Figure 7) begins as a fairly typical metabolic profile for a developing economy, with a high relative share of biomass, per-capita levels of material use well below 10 tonnes, and very low per capita consumption of fossil fuels. The share of metal ores and industrial minerals was however anomalously high even in 1970, standing at $40 \%$ and presumably reflecting Peru's historical legacy (since Spanish colonial times) as an important supplier of metals for export. From the early 1990s the already anomalously high share of metal ores and industrial minerals in Peru's DMC mix grew rapidly, as large scale investment into export oriented mining projects increased consumption of metal ores by over $9 \%$ p.a. compounding between 1992 and 2008. This expansion in mining increased Peru's DMC per capita to nearly 18 tonnes by 2008 , almost $70 \%$ higher than the global average. This level is higher than for many high income countries, further emphasizing that a high DMC boosted by mining activities does not necessarily flow through to high levels of affluence and household consumption or the capacity of government to spend in public infrastructure. 


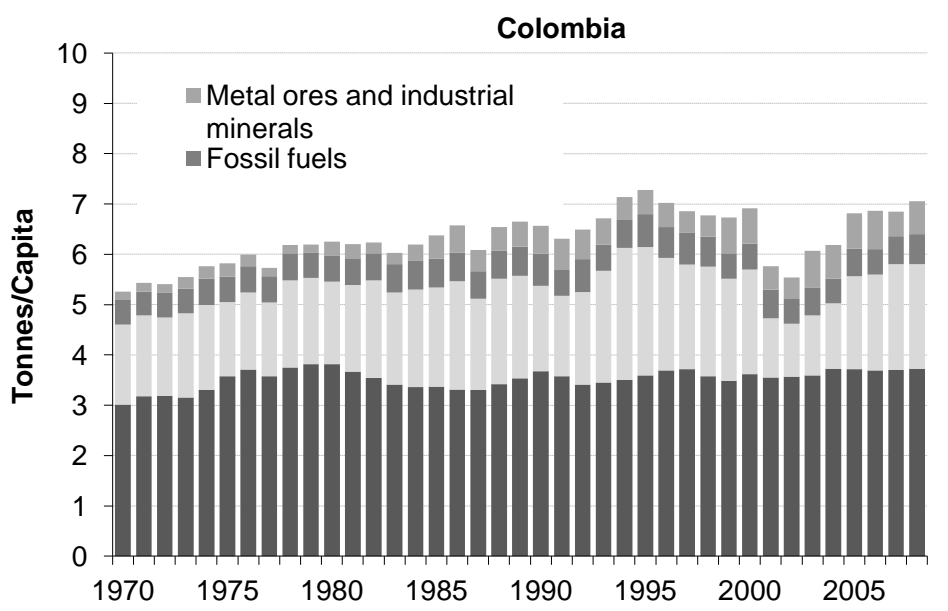

Figure 8 Domestic Materials Consumption (DMC) per capita, by four major materials categories, for Colombia

Figure 8 shows that Colombia's domestic material consumption levels decreased only marginally over the entire study period, and remain at relatively low levels, only $66 \%$ and $52 \%$ respectively of the world and regional averages. Growth among the different materials categories appears to have been relatively balanced, lacking the extreme growth in one sector, far beyond any conceivable local final demand for a material, which characterizes those economies pursuing a trading model based on exports of metals, as seen for Chile and Peru. Reference to data on Colombia's trade in fossil fuels in (IEA 2011b) does however show that it has greatly and consistently increased net fossil fuel exports since the mid 1980s, and as fossil fuels are not subject to high concentration factors prior to export, this leaves little imprint on Colombia's DMC profile. This characteristic of fossil fuel exports highlights one mechanism whereby increasing exports can contribute to an apparent improvement in resource efficiency (using the DMC/GDP metric), despite the deteriorating terms of trade, with unit values for exports stagnated or declining, as reported for most of the post 1980 period in both (Perez Rincon 2006) and (Vallejo et al. 2011).

The share of biomass in Colombia's DMC mix, still $53 \%$ in 2008, remains very high and is typical of a country which is at an early stage of industrialization. In this sense, Colombia is still at an early stage of its modernization process with a large fraction of its population in agriculture with associated low consumption levels and relatively low standards of material wellbeing. As discussed further in section 3.4, Colombia has nevertheless achieved greater gains in affluence from its relatively minor growth in material input than would be expected if it followed the material intensity trends more typical of the region. 


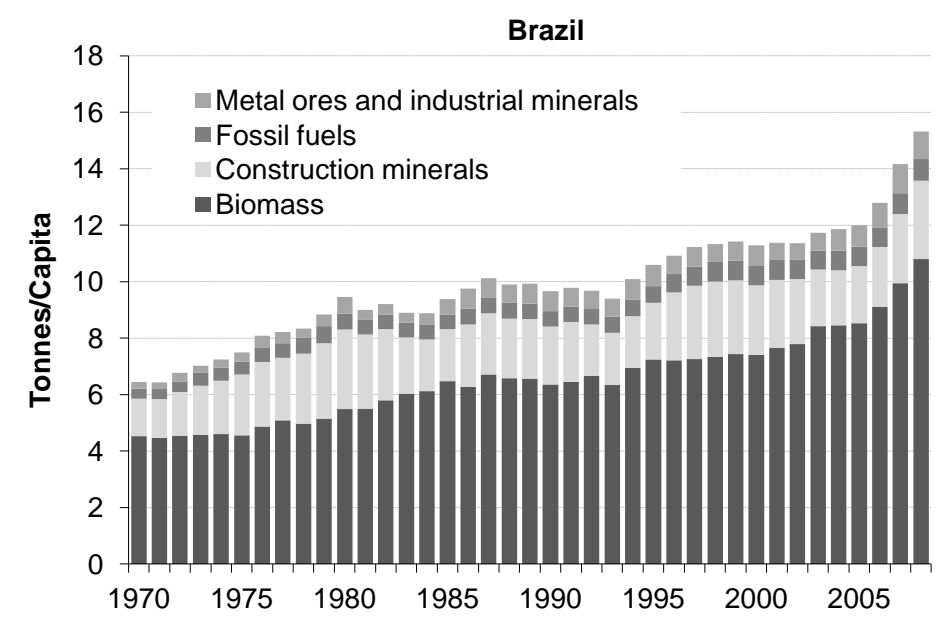

Figure 9 Domestic Material Consumption (DMC) per capita, by four major materials categories, for Brazil

The evolution of Brazil's pattern of DMC shares over the study period, as shown in Figure 9, is particularly interesting, in that it goes against the usual trend seen in a modernizing country. Despite considerable industrialization and urbanization, and strong associated growth in total DMC, the relative share of biomass in Brazil's DMC mix was virtually the same in 2008 as it was in 1970, constituting a very high $70 \%$ of the total. This goes against the trend of industrial modernization, where countries grow the share of mineral inputs (fossil fuels, metals and construction materials) at the cost of biomass. This usually predictable trend results from the need of a modern industrial society to break free of the energy (and later material) constraints imposed by biomass growth rates (Sieferle 1982). In Brazil's case, not only did the share of biomass not decrease, but it has actually grown again from levels below $60 \%$ at the end of the 1970 s, with growth in tonnage terms accelerating to over $6 \%$ p.a. compounding from 2000 to 2008 .

Using the information on individual crop production available in (FAO 2011c), and applying harvest factors from (Wirsenius 2000) it is apparent that the great majority $(>70 \%)$ of this recent growth in biomass is attributable to growth in the sugar industry. Brazil has long had a very large sugar industry, which received a huge incentive to expand further from the mid 1970s when the government mandated blending of ethanol with automotive gasoline. The latest surge in growth, post 2000, can in large part be explained by greatly increased domestic and international demand for biofuels, both because they are perceived as a means to lower greenhouse gas emissions, and due to surging petroleum prices. Brazil in 2008 managed to supply some $27 \%$ of the total world energy exports under the IEA category of biofuels and waste (IEA 2011a). This is despite the fact that the great majority of Brazils ethanol production is used locally, with the 19\% exported in 2008 (of roughly 25 billion liters produced) representing a high point (Valdes 2011). On average, around one half of Brazil's sugar production was converted to ethanol over the most recent decade. 
Despite Brazil's massive expansion in biomass production, and the associated large impacts on agricultural sustainability and biodiversity as well as on smallholder communities, from (IEA 2011a) data it appears that in 2008, only 32\% of its total primary energy supply was met from biomass and waste. In the field of liquid fuels used for transport, where Brazils institutional efforts and raw capacity in biofuels production and use are exceptional, the contribution of liquid biofuels was only one quarter that of petroleum based fuels (IEA 2011a). This highlights the magnitude of the challenge of trying to meet a significant proportion of a modernizing economy from biofuels, even in a country with Brazil's prodigious Net Primary Productivity as indicated by (Imhoff et al. 2004).

\subsection{Material efficiency trends}

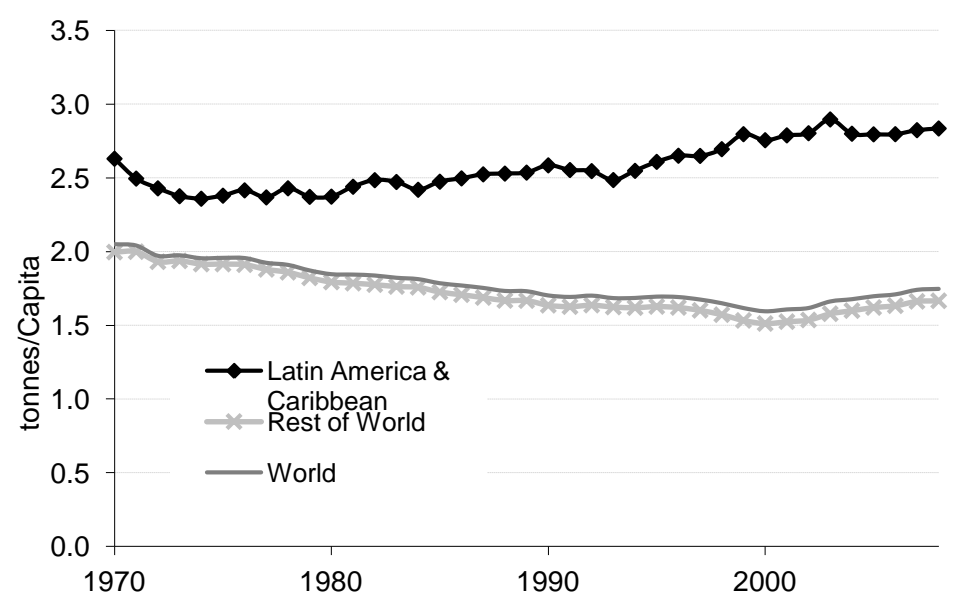

Figure 11 Material Intensity (MI) for Latin America and the Caribbean, Rest of the World, and World, for 1970 to 2008, in kg per \$US (materials are total domestic material consumption, dollars are constant year 2000 \$US, exchange rate based).

Figure 11 shows that Latin America and the Caribbean began the study period with a high material intensity relative to the rest of the world, and stagnated at this level for most of the $1970 \mathrm{~s}$ and $1980 \mathrm{~s}$, requiring $2.5 \mathrm{~kg}$ of materials used to produce each $\$$ of added value. During this period, global materials efficiency improved, so the region fell further behind in its relative capacity to produce economic gains from it s natural resources. From 1993, driven by the economic opening to the world market and vast investments in export oriented primary resources sectors, the region's material efficiency began to deteriorate, so that by the year 2000, the region needed nearly twice the global average input of material to produce one unit of income. Since 2000, and for the first time in a century, global material efficiency started to decline, preventing the gap between Latin America and the world from widening further.

Different countries have demonstrated different trends in their individual material efficiency. Figure 12 contrasts developments in the four focus countries, Chile, Brazil, Peru and Colombia. 


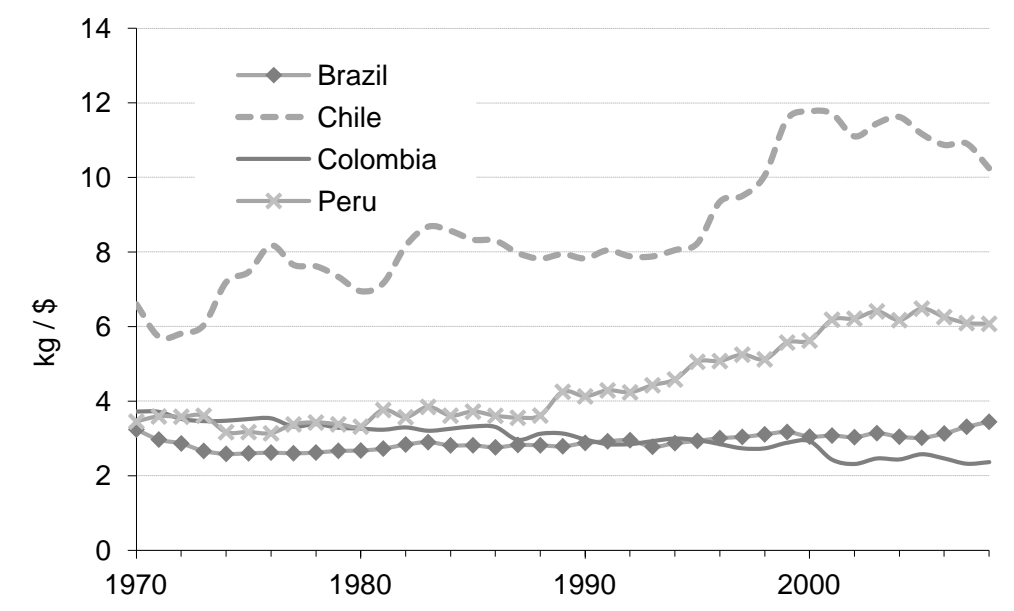

Figure 12 Material Intensity (MI) for Brazil, Chile, Colombia, and Peru. GDP used is exchange rate based constant year 2000 \$US.

Chile's material intensity has grown strongly over time and was over $10 \mathrm{~kg}$ per US\$ by 2008 , or about six times the global average. It reflects the degree to which Chile's economy depends on its non-ferrous mining sector, and the highly unfavorable physical balance of trade that results when an economy invests little to add value to this primary resource beyond concentrating it. Peru is increasingly on a similar trajectory because of the large expansion of non-ferrous metals production, for export, that has occurred since the 1990s. Colombia's and Brazil's material intensity have stayed much closer to the regional average for the last four decades, reflecting a greater balance between sectors of the economy, with much less reliance on nonferrous metals. Brazil's resource intensity, however, has increased recently, largely reflecting the recent expansion in biomass (especially biofuels and food).

Overall, the efficiency of material use in Latin America and Caribbean is severely impacted by the resource hunger of development in other parts of the world, and the region's moves to accommodate that demand by greatly expanding its primary resources sectors, in effect taking on the role of an extended hinterland for external economies. This economic path entails these countries taking on the increased environmental and social impacts that come with resource extraction on a massive scale.

\subsection{Drivers of material use}

In this section we use a variant on the original $\mathrm{I}=\mathrm{P} \times \mathrm{A} \times \mathrm{T}$ (IPAT) framework proposed in (Ehrlich and Holdren 1971), to analyze the relative importance of different drivers of the environmental impact of interest, in this case DMC, for the subset of four focus countries and for Latin America and the Caribbean as a whole. As in the original formulation, $\mathrm{P}$ is population, $\mathrm{A}$ is affluence calculated as GDP / population, and as I is DMC, the technological coefficient (T) is just materials intensity. In order to be able to allocate the contribution to the total growth in I accounted for by changes in each of the individual drivers $\mathrm{P}, \mathrm{A}$, and T, which total to 
$100 \%$, the IPAT factors have been transformed to logarithmic form, applying the methods set out in (Herendeen 1998).

Table 1 shows that population growth was broadly comparable to increasing affluence as a driver of DMC growth for most periods, and actually exceeded it in importance in the post debt crisis decade $(1980-1990)$, where affluence decreased and so acted to moderate DMC growth. This pattern is similar to the global pattern noted in (UNEP 2011), although very different to that noted for the Asia-Pacific region in (Schandl and West 2010) where affluence was always by far the strongest driver of growing DMC. It is only for the most recent period that growing affluence begins to exert a similarly dominant role in Latin America and the Caribbean. Of particular interest is the role of materials intensity, which has acted to exacerbate growth in DMC in the region in each period except the earliest, 1970 to 1980 . The detail provided for focus countries also makes clear that materials intensity is increasing at this level too. This is significant in that the regional increase is not produced by an increasing share of regional economic activity moving to lower efficiency economies, while the region's constituent economies continue to decrease their materials intensity on an individual basis, as has been recorded for other regions e.g. (UNEP 2011). In Latin America's case, most countries are developing economies which move them ever further from achieving even a relative decoupling of resources use from economic prosperity. Maintaining this mode of development necessarily implies ever greater environmental impact, as measured by DMC, just to maintain current levels of GDP. The environmental impact can be expected to increase very rapidly in the future if we then factor in people's aspirations for increased individual affluence coupled with ongoing population growth.

It can be expected that ceteris paribus, materials intensity will increase over periods of decreasing primary commodity prices, and decrease during commodity price booms, in economies which have large primary exports sectors. The commodity price charts in (Radetzki 2006) suggest this dynamic may largely explain the widespread deteriorations seen over the 1980s and 1990s, and the very large improvement seen in the most resources based economy, Chile, over the most recent decade. It does not, however, explain the major improvements seen in the 1970s. These may have resulted in part from greater attention to energy and materials efficiency prompted by the rapid increase in petroleum prices.

\begin{tabular}{lrrrrr}
\hline $1970-1980$ & $\Delta \mathrm{I} \%$ & $\Delta \mathrm{I}$ (million tonnes) & $\Delta \log \mathrm{P}$ & $\Delta \log \mathrm{A}$ & $\Delta \log \mathrm{T}$ \\
\hline Brazil & $86 \%$ & 531,5 & $38 \%$ & $93 \%$ & $-31 \%$ \\
Chile & $40 \%$ & 55,3 & $46 \%$ & $38 \%$ & $15 \%$ \\
Colombia & $50 \%$ & 55,9 & $57 \%$ & $75 \%$ & $-32 \%$ \\
Peru & $37 \%$ & 35,0 & $87 \%$ & $26 \%$ & $-13 \%$ \\
Latin America & $52 \%$ & $1,117,4$ & $53 \%$ & $71 \%$ & $-24 \%$ \\
\hline $1980-1990$ & $\Delta \mathrm{I} \%$ & $\Delta \mathrm{I}$ (million tonnes) & $\Delta \log \mathrm{P}$ & $\Delta \log \mathrm{A}$ & $\Delta \log \mathrm{T}$ \\
\hline Brazil & $26 \%$ & 295,5 & $90 \%$ & $-23 \%$ & $32 \%$ \\
Chile & $63 \%$ & 122,4 & $34 \%$ & $42 \%$ & $24 \%$ \\
Colombia & $30 \%$ & 49,7 & $81 \%$ & $55 \%$ & $-36 \%$ \\
Peru & $15 \%$ & 19,4 & $164 \%$ & $-221 \%$ & $157 \%$ \\
Latin America & $22 \%$ & 713,7 & $101 \%$ & $-44 \%$ & $43 \%$ \\
\hline $1990-2000$ & $\Delta \mathrm{I} \%$ & $\Delta \mathrm{I}$ (million tonnes) & $\Delta \log \mathrm{P}$ & $\Delta \log \mathrm{A}$ & $\Delta \log \mathrm{T}$ \\
\hline Brazil & $36 \%$ & 520,4 & $50 \%$ & $32 \%$ & $18 \%$ \\
Chile & $179 \%$ & 567,9 & $15 \%$ & $45 \%$ & $40 \%$
\end{tabular}




\begin{tabular}{lrrrrr} 
Colombia & $26 \%$ & 57,0 & $78 \%$ & $29 \%$ & $-7 \%$ \\
Peru & $101 \%$ & 150,8 & $25 \%$ & $30 \%$ & $44 \%$ \\
Latin America & $43 \%$ & $1,691,6$ & $42 \%$ & $42 \%$ & $16 \%$ \\
\hline $2000-2008$ & $\Delta \mathrm{I} \%$ & $\Delta \mathrm{I}$ (million tonnes) & $\Delta \log \mathrm{P}$ & $\Delta \log \mathrm{A}$ & $\Delta \log \mathrm{T}$ \\
\hline Brazil & $50 \%$ & 975,1 & $24 \%$ & $45 \%$ & $30 \%$ \\
Chile & $21 \%$ & 184,3 & $45 \%$ & $128 \%$ & $-73 \%$ \\
Colombia & $15 \%$ & 42,5 & $86 \%$ & $162 \%$ & $-148 \%$ \\
Peru & $71 \%$ & 211,8 & $19 \%$ & $66 \%$ & $14 \%$ \\
Latin America & $35 \%$ & $2,006,2$ & $32 \%$ & $59 \%$ & $9 \%$ \\
\hline
\end{tabular}

One focus country which has consistently gone against the trend towards higher materials intensities is Colombia. While DMC continued to grow there in each period, it consistently improved its material intensity in each period studied. In the best case, this would indicate that it has successfully found a development path which is more balanced across sectors, and is overall making consistent progress in extracting higher value from each unit of primary input. In doing this it would at least have achieved "weak" decoupling, a necessary step towards longer term sustainability. A less optimistic possible explanation for Colombia's trajectory may lie in it having consistently raised exports of fossil fuels since the mid 1980s, in which case this trajectory may reverse in the medium to long term if reserves deplete. In any case, the fact that Colombia's performance is unique among the major Latin American economies would seem to merit further studies which, probably requiring resolution of materials intensity at sectoral level and extending to downstream sectors where practicable.

\section{General discussion and conclusions}

Latin America and the Caribbean has been less efficient in creating income from its natural resources than the rest of the world, which is reflected in the regions material intensity being over one and a half times the global average. It may be argued, however, that the material intensity of the region is artificially high because a large fraction of the substance or service of value embodied in the primary materials produced is actually consumed outside of the region, while the associated waste and emissions remain in the region and add to a large DMC account. If those primary materials were allocated to the final consumers of the resources, the region's apparent material consumption would decrease and material efficiency would improve. Recent research has found that material use based on final consumption would be $21 \%$ smaller in the case of Argentina but only 6\% smaller in the case of Brazil (Bruckner et al. 2012). A reallocation of consumption for Chile would, given the great importance of metal ores in that country's DMC account, almost certainly yield a very large decrease.

The trends in resource efficiency revealed in this study suggest that securing a prosperous and sustainable future for Latin America over the long term will require that the individual nations develop their capacity to use natural resources more efficiently, extracting more value per unit of resources used. Moving more of the region's productive activities further up the value adding chain from the commodities initially extracted would achieve this. This should also make the region's economies less vulnerable to the type of terms of trade shocks discussed in (Adler and Sosa 2011), and also incur less of the environmental impacts which typically accrue from the early materials and energy intensive phases of materials processing. As a shift to 
higher resource efficiency would go directly against the trends seen since the 1990s, it appears likely that government strategies and explicit public policies encouraging higher resource efficiency would be required to achieve this change. The information provided by material flow accounting can support the policy formation process in several ways. Material flow accounting can help to establish the information base on physical resource flows required to reach more fully informed social compromises in what has traditionally been a policy field dominated by purely monetary measures. The physical dimensions covered by material flows accounting are crucial to the monitoring and evaluation of progress, against quantifiable targets, of policies aimed at lowering the environmental impacts of development.

Comparison of our results with some national accounts figures available from previous studies show our estimate for Chile to be notably higher than in (Giljum 2004) and (Russi et al. 2008), and slightly higher than the estimate for Colombia in (Vallejo et al. 2011) which is mainly due to methodological improvements which have occurred since. The MFA data for Brazil is especially important, and there was no equivalent from previous peer-reviewed literature. Trends for the largest and most influential Latin American economy can now be compared with the data for the other BRIC countries, Russia, India and China, who together dominate current trends in global material use.

The observed pattern for Latin America and the Caribbean, where increasing affluence and population are broadly comparable in their contributions to growing material use, implies that a prosperous new middle has not emerged to the extent seen in some other regions, most notably in Asia. This is consistent with analysis such as that by (Milanovic and Yitzhaki 2002), who found that "The Asian continent consists of countries with widely different per capita income levels and moderate withincountry inequalities. Latin America is a continent composed of countries with similar per capita incomes, but with large within-country inequalities". Furthermore, (Portes and Hoffman 2003) found that income inequality in LA increased with the ending policies directed towards import substitution industrialization, with wealth remaining concentrated in the top decile of the population while contraction in both the public sector and stagnation of the formal labor sector adversely impacted the middle and lower classes. One of the responses noted to these impacts has been an expansion in the informal sector, characterized by subsistence and semi-clandestine economic activities. So long as this pattern continues in Latin America, it can be expected to preserve existing social divisions.

There is an extensive literature which makes a case that, in economies dominated by extractive industries, the benefits derived from these industries tend not to be shared with the communities where the extraction occurs(Bunker and Ciccantell 2003, Bunker 1984b, Ciccantell and Bunker 2002) or at least to increase inequality in those communities (Reeson, Measham and Hosking 2012). In some work the "community" in which extraction occurs is extended to entire nation e.g. (Ciccantell and Bunker 2002), while in others the community is much more local in scope. Other dynamics, such as the restriction of smallholder access to forests to accommodate mining interests (Cotula, Dyer and Vermeulen 2008), could be of concern to counties pursuing development via intensified extractive activity. The authors hope that the empirical data on materials use and efficiency assembled for this study might also

Comment [mea069 1]: Discuss thi Hoffman (2003) 
serve to underpin future research linking material use and material efficiency trends in the region to human development trajectories and outcomes, and to issues of equality.

\section{Acknowledgements}

This research has been supported by the United Nations Environment Program regional office for Latin America and the Caribbean. The authors wish to thank Graciela Metternich of the UNEP office for her support. We also thank Tom Measham and Luis Rodriguez for their feedback to a draft version and three anonymous reviewers for their very helpful comments.

\section{References}

Adler, G. \& S. Sosa. 2011. Commodity Price Cycles: The Perils of Mismanaging the Boom. IMF Working Papers.

Bartelmus, P. (2003) Dematerialization and capital maintenance: two sides of the sustainability coin. Ecological Economics, 46, 61-81.

Bartelmus, P. (2007) SEEA-2003: Accounting for sustainable development? Ecological Economics, 61, 613-616.

Behrens, A., S. Giljum, J. Kovanda \& S. Niza (2007) The material basis of the global economy: Worldwide patterns of natural resource extraction and their implications for sustainable resource use policies. Ecological Economics, 64, 444-453.

Bértola, L. \& J. A. Ocampo. 2012. Latin America's debt crisis and the "lost decade". Institute for the study of the Americas.

Bruckner, M., S. Giljum, C. Lutz \& W. K.S. (2012) Materials embodied in international trade - Global material extraction and consumption between 1995 and 2005. Global Environmental Change.

Bunker, S. \& P. Ciccantell (2003) Generative sectors and the new historical materialism: Economic ascent and the cumulatively sequential restructuring of the world economy. Studies in Comparative International Development (SCID), 37, 3-30.

Bunker, S. G. (1984a) Modes of Extraction, Unequal Exchange, and the Progressive Underdevelopment of an Extreme Periphery: The Brazilian Amazon, 1600 - 1980. American Journal of Sociology, 89, 1017-1064.

Bunker, S. G., 89, 1017-1064. (1984b) Modes of Extraction, Unequal Exchange, and the Progressive Underdevelopment of an Extreme Periphery: The Brazilian Amazon, 1600 - 1980. American Journal of Sociology, 89 10171064.

Ciccantell, P. S. \& S. G. Bunker (2002) International Inequality in the Age of Globalization: Japanese Economic Ascent and the Restructuring of the Capitalist World-Economy. journal of world-systems research, 8, 62-98.

Cotula, L., N. Dyer \& S. Vermeulen. 2008. Fuelling Exclusion? The biofuels boom and poor people's access to land. London: FAO and IIED.

Ehrlich, P. R. \& J. P. Holdren (1971) Impact of Population Growth. Science, 171, 1212-1217.

Eurostat. 2011. Economy Wide Material Flow Accounts (EW-MFA): Compilation Guidelines for Eurostat's 2011 EW-MFA questionnaire 
FAO. 2011a. Subscribers section - Bulk downloads - Food balance sheets. Food and agriculture organization of the United Nations.

--. 2011b. Subscribers section - Bulk downloads - Forestry. . Food and agriculture organization of the United Nations.

--.. 2011c. Subscribers section - Bulk downloads - Production. . Food and agriculture organization of the United Nations.

--. 2011d. Subscribers section - Bulk downloads - Trade. Food and agriculture organization of the United Nations.

Fischer-Kowalski, M. (1998) Society's Metabolism:The Intellectual History of Materials Flow Analysis, Part I, I 860- I 970. Journal of Industrial Ecology, 2,61-78.

Fischer-Kowalski, M., F. Krausmann, S. Giljum, S. Lutter, A. Mayer, S. Bringezu, Y. Moriguchi, H. Schütz, H. Schandl \& H. Weisz (2011) Methodology and Indicators of Economy-wide Material Flow Accounting. Journal of Industrial Ecology, 15, 855-876.

Gerst, M. D. (2008) Revisiting the Cumulative Grade-Tonnage Relationship for Major Copper Ore Types. Economic Geology, 103, 615-628.

Gierlinger, S. \& F. Krausmann (2012) The Physical Economy of the United States of America. Journal of Industrial Ecology, 16, 365-377.

Giljum, S. (2004) Trade, Materials Flows, and Economic Development in the South: The Example of Chile. Journal of Industrial Ecology, 8, 241-261.

Giljum, S. \& N. Eisenmenger (2004) North-South Trade and the Distribution of Environmental Goods and Burdens: a Biophysical Perspective. The Journal of Environment and Development, 13, 73-100.

Gonzalez-Martinez, A. C. \& H. Schandl (2008) The biophysical perspective of a middle income economy: Material flows in Mexico. Ecological Economics, 68, 317-327.

Haberl, H., M. Fischer-Kowalski, F. Krausmann, H. Weisz \& V. Winiwarter (2004) Progress towards sustainability? What the conceptual framework of material and energy flow accounting (MEFA) can offer. Land Use Policy, 21, 199-213.

Herendeen, R. A. 1998. Ecological Numeracy: Quantitative Analysis of Environmental Issues. New York: John Wiley \& Sons Inc.

IEA. 2011a. Energy balances of Non-OECD countries. Paris: International Energy Agency.

--.. 2011b. Energy statistics of Non-OECD countries. Paris: International Energy Agency.

--. 2011c. Energy statistics of OECD countries. Paris: International Energy Agency.

Imhoff, M. L., Lahouari Bounoua, Taylor Ricketts, Colby Loucks, Robert Harriss \& W. T. Lawrence. 2004. Global Patterns in Net Primary Productivity (NPP) Data distributed by the Socioeconomic Data and Applications Center (SEDAC): .

Krausmann, F., S. Gingrich, N. Eisenmenger, K.-H. Erb, H. Haberl \& M. FischerKowalski (2009) Growth in global materials use, GDP and population during the 20th century. Ecological Economics, 68, 2696 - 2705.

Krausmann, F., S. Gingrich \& R. Nourbakhch-Sabet (2011) The Metabolic Transition in Japan. Journal of Industrial Ecology, 15, 877-892. 
Matos, G. 2009. Commodity Flows - (Unpublished spreadsheet collation of USGS data for series of major mineral commodities). USGS.

Milanovic, B. \& S. Yitzhaki (2002) Decomposing World Income Distribution: Does the World have a Middle Class. Review of Income and Wealth, 48, 155-178.

Mudd, G. M. 2007a. Master spreadsheets compiling Australian mining production data. Department of Civil Engineering, Monash University and Mineral Policy Institute.

Mudd, G. M. 2007b. The Sustainability of Mining in Australia : Key Production Trends and Their Environmental Implications for the Future. Department of Civil Engineering, Monash University and Mineral Policy Institute.

Perez Rincon, M. A. (2006) Colombian international trade from a physical perspective: Towards an ecological Prebisch thesis. Ecological Economics, 59,519-529.

Portes, A. \& K. Hoffman (2003) Latin American Class Structures: Their Composition and Change during the Neoliberal Era. Latin American Research Review, 38, 41-82

Radetzki, M. (2006) The anatomy of three commodity booms. Resources Policy, 31, 56-64.

Reeson, A. F., T. G. Measham \& K. Hosking (2012) Mining activity, income inequality and gender in regional Australia*. Australian Journal of Agricultural and Resource Economics, 56, 302-313.

Russi, D., A. C. Gonzalez-Martinez, I. C. Silva-Macher, S. Giljum, J. Martínez-Alier \& M. C. Vallejo (2008) Material Flows in Latin America. Journal of Industrial Ecology, 12, 704-720.

Schandl, H. \& N. Eisenmenger (2006) Regional Patterns in Global Resource Extraction. Journal of Industrial Ecology, 10, 133-147.

Schandl, H. \& I. West (2010) Resource use and resource efficiency in the AsiaPacific region. Global Environmental Change - Human and Policy Dimensions, 20, 636-647.

Schandl, H. \& J. West (2012) Material Flows and Material Productivity in China, Australia, and Japan. Journal of Industrial Ecology, 16, 352-364.

Sieferle, R. P. 1982. Der unterirdische Walt: Energiekrise und Industrielle Revolution Munich: C.H. Beck.

UN Statistics Division. 2011a. Commodity Trade Statistics Database United Nations.

UN Statistics Division. 2011b. Industrial Commodity Production Statistics Database 1950 - 2008. ed. U. Nations. New York.

UNEP. 2011. Resource Efficiency: Economics and Outlook for Asia and the Pacific. Bangkok: United Nations Environment Programme.

USGS. 2011. Commodity statistics and information. USGS.

Valdes, C. 2011. Can Brazil Meet the World's Growing Need for Ethanol? In Amber Waves, 38-44. United States Department of Agriculture.

Vallejo, M. C. (2010) Biophysical structure of the Ecuadorian economy, foreign trade, and policy implications. Ecological Economics, 70, 159-169.

Vallejo, M. C., M. A. Pérez Rincón \& J. Martinez-Alier (2011) Metabolic Profile of the Colombian Economy from 1970 to 2007. Journal of Industrial Ecology, 15, 245-267.

Weisz, H., F. Krausmann, C. Amann, N. Eisenmenger, K. H. Erb, K. Hubacek \& M. Fischer-Kowalski (2006) The physical economy of the European Union: 
cross-country comparison and determinants of material consumption.

Ecological Economics, 58, 676-698.

Wirsenius, S. 2000. Human Use of Land and Organic Materials: Modeling the

Turnover of Biomass in the Global Food System. In Department of Physical

Resource Theory. Göteborg: Chalmers University of Technology.

World Bank. 2011. World Development Indicators 2011. World Bank. 